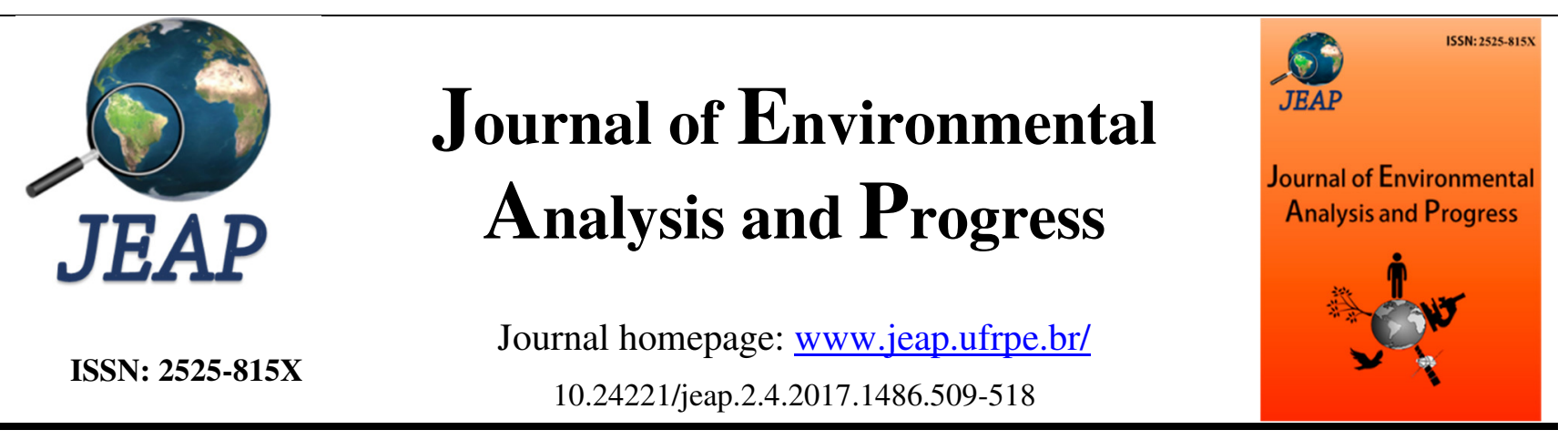

\title{
Parâmetros fisiológicos de variedades de cana-de-açúcar submetidas a distintos regimes hídricos
}

\section{Physiological parameters of sugarcane varieties under different water regimes}

Marcos Vinicius Pereira da Silva ${ }^{a}$, Josiane Fonteneles Silva ${ }^{a}$, Elizandra dos Santos Sousa da Silva ${ }^{a}$, Aderson Soares de Andrade Júnior ${ }^{\mathrm{b}}$, Francisco Edinaldo Pinto Mousinho ${ }^{\mathrm{a}}$

a Universidade Federal do Piaui-UFPI, Programa de Pós-Graduação em Agronomia, Campus Universitário Ministro Petrônio Portella, Bairro Ininga, Teresina-PI. CEP: 64049-550. E-mail: marquim06vinicios@gmail.com; josianefonteneles@ hotmail.com; elizandrasilva96@gmail.com; fepmousi@ufpi.edu.br.

${ }^{\mathrm{b}}$ Embrapa Meio-Norte, Teresina, PI, Brasil. E-mail: aderson.andrade@embrapa.br.

A R T I C L E I N F O

Recebido 11 Jul 2017

Aceito 04 Ago 2017

Publicado 13 Out 2017

\begin{abstract}
A B S T R A C T
Soil water deficiency affects a large part of the world's cultivated areas, especially in semi-arid regions, provoking a reduction in plant growth and production, leading to socioeconomic losses. The study aimed to evaluate the physiological performance of five commercial varieties of sugar cane, in two seasons, when subjected to three different water regimes, aiming at the selection of genotypes more tolerant to water deficit and responsive to irrigation for cultivating soil and climate conditions of the northeast of Teresina-PI. Water regimes were imposed by the application of different irrigation blades based on the reference evapotranspiration (ETo) (water deficit 50\% ETo, full irrigation 100\% ETo and water surplus $150 \%$ ETo), during the period of 90 to 150 days after cutting (DAC). Physiological characteristics evaluated were photosynthesis rate, stomatal conductance, and transpiration, quantified to 15 and 45 days after the beginning of the charge of water schemes. The cultivars of sugarcane evaluated presented changes in the physiological mechanism depending on the availability of water in the soil and water tax regimes predisposition. It is concluded that the variety RB 962962 presented the best physiological performance when subjected to the regime of water deficiency. Under full irrigation and water surplus, RB962962 and RB 98710 varieties promoted the largest average of photosynthesis, stomatal conductance, and transpiration. The variety SP 791011 showed the highest stomatal sensitivity, reducing photosynthesis, conductance, and transpiration to 45 days after the deployment of water regimes, both as deficiency treatments for excess water. Keywords: Stomatal conductance, photosynthesis, transpiration.
\end{abstract}

\footnotetext{
R E S U M O

A deficiência hídrica do solo afeta grande parte das áreas cultivadas no mundo, principalmente nas regiões semiáridas, provocando uma redução do crescimento e da produção vegetal, acarretando prejuízos socioeconômicos. O estudo objetivou avaliar o desempenho fisiológico de cinco variedades comerciais de cana-deaçúcar, em duas épocas de avaliação, quando submetidas a três regimes hídricos distintos, visando a seleção de genótipos mais tolerantes ao déficit hídrico e responsivos à irrigação para cultivo nas condições edafoclimáticas da microrregião de Teresina-PI. Os regimes hídricos foram impostos pela aplicação de distintas lâminas de irrigação com base na evapotranspiração de referência (ETo) (Déficit hídrico 50\%, Irrigação plena $100 \%$ e Excedente hídrico $150 \%$ ETo), no período dos 90 aos 150 dias após o corte (DAC). As características fisiológicas avaliadas foram:
} 
taxa de fotossíntese, condutância estomática e transpiração, quantificadas aos 15 e 45 dias após o início da imposição dos regimes hídricos. As cultivares de cana-deaçúcar avaliadas apresentaram alterações no mecanismo fisiológico em função da disponibilidade de água no solo e do tempo de predisposição aos regimes hídricos impostos. Conclui-se que a variedade RB 962962 apresentou o melhor desempenho fisiológico quando submetida ao regime de deficiência hídrica. Em condições de irrigação plena e excedente hídrico as variedades RB 962962 e RB 98710 promoveram as maiores médias fisiológicas de fotossíntese, condutância estomática e transpiração. A variedade SP 791011 apresentou maior sensibilidade estomática, reduzindo a fotossíntese, a condutância e a transpiração, aos 45 dias após a implantação dos regimes hídricos, tanto nos tratamentos de deficiência como para o de excesso hídrico.

Palavras-Chave: Condutância estomática, fotossíntese, transpiração.

\section{Introdução}

A região Meio-Norte do Brasil (Piauí e Maranhão) destaca-se dentre as áreas de expansão para o cultivo de cana-de-açúcar, por apresentar condições edafoclimáticas e de logística propícias ao cultivo da cana-de-açúcar. Porém, há a necessidade de indicação de genótipos comerciais, com elevado potencial de produção de açúcar e álcool, tolerantes a deficiência hídrica, para cultivo em áreas de sequeiro, bem como responsivos à água, para cultivo em regime irrigado. A deficiência hídrica do solo é um problema que afeta grande parte das áreas cultivadas no mundo, principalmente nas regiões semiáridas, o que provoca uma redução do crescimento e da produção vegetal, acarretando prejuízos socioeconômicos (Munns, 2002).

A água é o principal fator limitante do crescimento da cana-de-açúcar (Inman-Bamber \& Smith, 2005), reduzindo primeiramente o alongamento e a divisão celular e consequentemente o desenvolvimento das folhas (Inman-Bamber, 2004). Alguns genótipos de cana-de-açúcar mostram rápida recuperação após eventos de seca (Landell et al., 2005), sendo a tolerância à seca relacionada a mecanismos fisiológicos capazes de manter o crescimento da planta em condição restritiva, tais como fechamento estomático e manutenção da atividade fotossintética (Machado et al., 2010).

Glenn et al. (2000) afirmam que, à medida que diminui a disponibilidade de água no solo, a taxa de transpiração decresce em decorrência do fechamento dos estômatos, sendo esse um dos principais mecanismos de defesa das plantas contra a perda exagerada de água, e eventual morte por dessecação. Segundo Chaves et al. (1987) e Rodrigues et al. (1987), uma das principais respostas das plantas à deficiência hídrica é o fechamento dos estômatos, o que provoca uma diminuição do $\mathrm{CO}_{2}$ para o mesófilo foliar, diminuindo as taxas de fotossíntese. Dessa forma, as avaliações fisiológicas, como as medidas de trocas gasosas (fotossíntese, condutância estomática e transpiração), podem ser utilizadas para avaliação dos efeitos da deficiência hídrica em plantas.

O estudo objetivou avaliar o desempenho fisiológico de variedades comerciais de cana-deaçúcar, visando a seleção de genótipos mais tolerantes ao déficit hídrico e responsivos à irrigação para cultivo nas condições edafoclimáticas da microrregião de Teresina, Piaui.

\section{Material e Métodos}

$\mathrm{O}$ experimento foi realizado na área experimental da Embrapa Meio Norte, localizada no município de Teresina-PI. O clima da região caracteriza-se por apresentar temperatura média de $27,9^{\circ} \mathrm{C}$, umidade relativa do ar média de $69,2 \%$ e precipitação, média anual de 1.343,4 mm (Bastos \& Andrade Júnior, 2014). O solo da área experimental é um Argissolo Vermelho-Amarelo eutrófico, de textura franco-arenosa (MELO et al., 2014).

A cana-de-açúcar foi avaliada no terceiro ciclo de cultivo, com o último corte realizado no dia 18 do julho de 2013. Até 90 dias após o segundo corte (DAP), a lâmina de irrigação foi uniforme. A partir de 90 DAC foram implantados os regimes hídricos e estes se estenderam até os 150 DAP.

O delineamento em blocos casualizado foi utilizado com quatro repetições. $\mathrm{O}$ ensaio foi constituído pela combinação de cinco variedades de cana-de-açúcar RB 962962 (RB962962), RB 98710 (RB98710), RB 867515 (RB867515), SP 791011 (SP791011) e VAT 90212 (VAT90212), e três regimes hídricos (deficiência hídrica-DH $50 \%$, irrigação plena-IP $100 \%$ e excesso hídricoEH $150 \%$ da ETo), estimada pelo método de Penman-Monteith (Allen et al., 1998), usando dados climáticos, obtidos da estação agrometeorológica automática instalada próxima a área experimental. As variedades foram plantadas em fileiras duplas de dez metros de comprimento, em um espaçamento de 2,0 m entre fileiras duplas e $0,50 \mathrm{~m}$ entre as linhas de fileira. 
O sistema de irrigação utilizado foi o gotejamento subsuperficial, com linhas gotejadoras em polietileno, espaçadas de $2,0 \mathrm{~m}$ entre si e enterradas a $0,25 \mathrm{~m}$ de profundidade, com vazão nominal de $2 \mathrm{~L} \cdot \mathrm{h}^{-1}$. Cada linha possui uma tubulação independente para cada regime avaliado, sendo nela instalados hidrômetros flangeados de 2" de diâmetro, para controle e medição do volume de água aplicado em cada regime hídrico. Na entrada dessa tubulação principal, foi instalado um cavalete, que permite a conexão de uma bomba hidráulica TMB, com vazão de 60 L.h ${ }^{-1}$, usada para a injeção dos fertilizantes. A irrigação foi realizada sempre no período da manhã, nos respectivos dias: segunda, quarta e sexta-feira.

A adubação da área foi efetuada, com base na análise de fertilidade do solo, via fertirrigação, com frequência semanal para nitrogênio (ureia) e potássio (cloreto de potássio) e quinzenalmente para o fósforo (MAP) e micronutrientes (molibidato de sódio, óxido de zinco, óxido manganês, ácido borico) conforme o parcelamento recomendado por Andrade Júnior et al. (2012).

A umidade do solo foi medida diariamente, no período da manhã e antes da aplicação da irrigação, com base na técnica da capacitância elétrica, utilizando uma sonda FDR (Diviner®), por se tratar de um aparelho que fornece leituras rápidas $\mathrm{e}$ precisas $\mathrm{em}$ profundidade. A sonda do equipamento foi inserida, no momento da leitura, em tubos de acesso em PVC, em número de três para cada regime hídrico, instalados espaçadamente em cada bloco experimental, com as profundidades de medição: $0,10 \mathrm{~m}, 0,20 \mathrm{~m}, 0,30 \mathrm{~m}, 0,40 \mathrm{~m}$ e 0,50 $\mathrm{m}$.

Durante o período de esposição dos regimes hidricos foram efetuadas duas avaliações fisiológicas (aos 15 e 45 dias após o início da aplicação dos regimes hídricos), sempre realizadas, no horário de 7 às 11 horas, na porção média da folha +2 (segunda folha mais jovem completamente expandida), sendo essa bem iluminada, madura, de idade similar e mesma disposição no colmo, utilizando uma planta diferente em cada avaliação. As medições das taxas de fotossíntese, condutância estomática e transpiração foram efetuadas utilizando-se um analisador de gás a infravermelho IRGA (modelo LI 6400XT), com fluxo de ar de $500 \mathrm{~mL} \cdot \mathrm{min}^{-1} \mathrm{e}$ fonte de luz acoplada de $2.000 \mu \mathrm{mol} . \mathrm{m}^{-2} . \mathrm{s}^{-1}$. Os dados de fotossíntese, condutância estomática e transpiração, nas duas épocas avaliadas, obtidos foram submetidos a análise de variância com o auxílio do programa estatístico SAS (SAS
Institute, 2014). A comparação de médias foi realizada pelo teste de Tukey, a $5 \%$ de probabilidade, e os gráficos foram elaborados com auxílio do programa Excel 2010.

\section{Resultados}

$\mathrm{Na}$ Tabela 1 são apresentados os valores dos totais das lâminas de irrigação aplicadas no período inicial (antes da imposição dos regimes hídricos diferenciados) e as lâminas acumuladas até a data de cada avaliação fisiológica (aos 15 e 45 dias após o início da imposição dos regimes hídricos diferenciados-DAI).

Tabela 1. Valores das lâminas de irrigação aplicadas no período inicial (antes da imposição dos regimes hídricos diferenciados), e as lâminas acumuladas até a data de cada avaliação.

\begin{tabular}{cccc}
\hline \multirow{2}{*}{ Avaliação } & \multicolumn{3}{c}{ Regime hídrico $(\mathbf{m m})$} \\
& DH & IP & EH \\
\hline Fase inicial & 53,73 & 53,73 & 53,73 \\
$1^{\circ}(15 \mathrm{DAI})$ & 91,74 & 129,72 & 167,71 \\
$2^{\circ}(45 \mathrm{DAI})$ & 145,22 & 236,68 & 328,14 \\
\hline
\end{tabular}

No período inicial, antes da imposição dos regimes hídricos diferenciados no solo, foi aplicada uma lâmina de irrigação uniforme de $53,73 \mathrm{~mm}$, suficiente para o adequado estabelecimento das plantas e desenvolvimento inicial da cultura. Durante a fase de imposição dos regimes hídricos, as lâminas de irrigação foram aumentando gradualmente, porém, em velocidades distintas, dependendo do nível de reposição de água aplicado em cada regime hídrico. Essa aplicação diferenciada de água foi responsável pela manutenção dos regimes hídricos e conteúdos diferenciados de água no solo, conforme havia sido planejado.

A Figura 1 apresenta a variação do conteúdo de água no solo, nas camadas de 0,10 a $0,50 \mathrm{~m}$, obtida com a aplicação diferenciada das lâminas de irrigação aplicadas durante a fase de imposição dos regimes hídricos diferenciados no solo.

Em termos de umidade média no perfil de solo de 0 a $0,5 \mathrm{~m}$, os níveis de umidade seguiram a ordem crescente dos regimes hídricos aplicados, ou seja, os valores de umidade no solo com a aplicação dos regimes hídricos de IP e EH, foram sempre superiores ao regime hídrico de $\mathrm{DH}$, que recebeu sempre as menores lâminas de irrigação acumuladas (Tabela 1).

Os conteúdos de água no solo com a imposição dos regimes hídricos de IP e EH mantiveram-se sempre na faixa dos $20 \%$ aos $25 \%$, sempre próximos à capacidade de campo do solo 
(30\%), enquanto que no regime de $\mathrm{DH}, \mathrm{o}$ conteúdo de água no solo variou de $20 \%$ a $15 \%$, indicando ter ocorrido deficiência hídrica no solo, visto que a umidade crítica (UC) para a cana-deaçúcar é de $22,5 \%$.
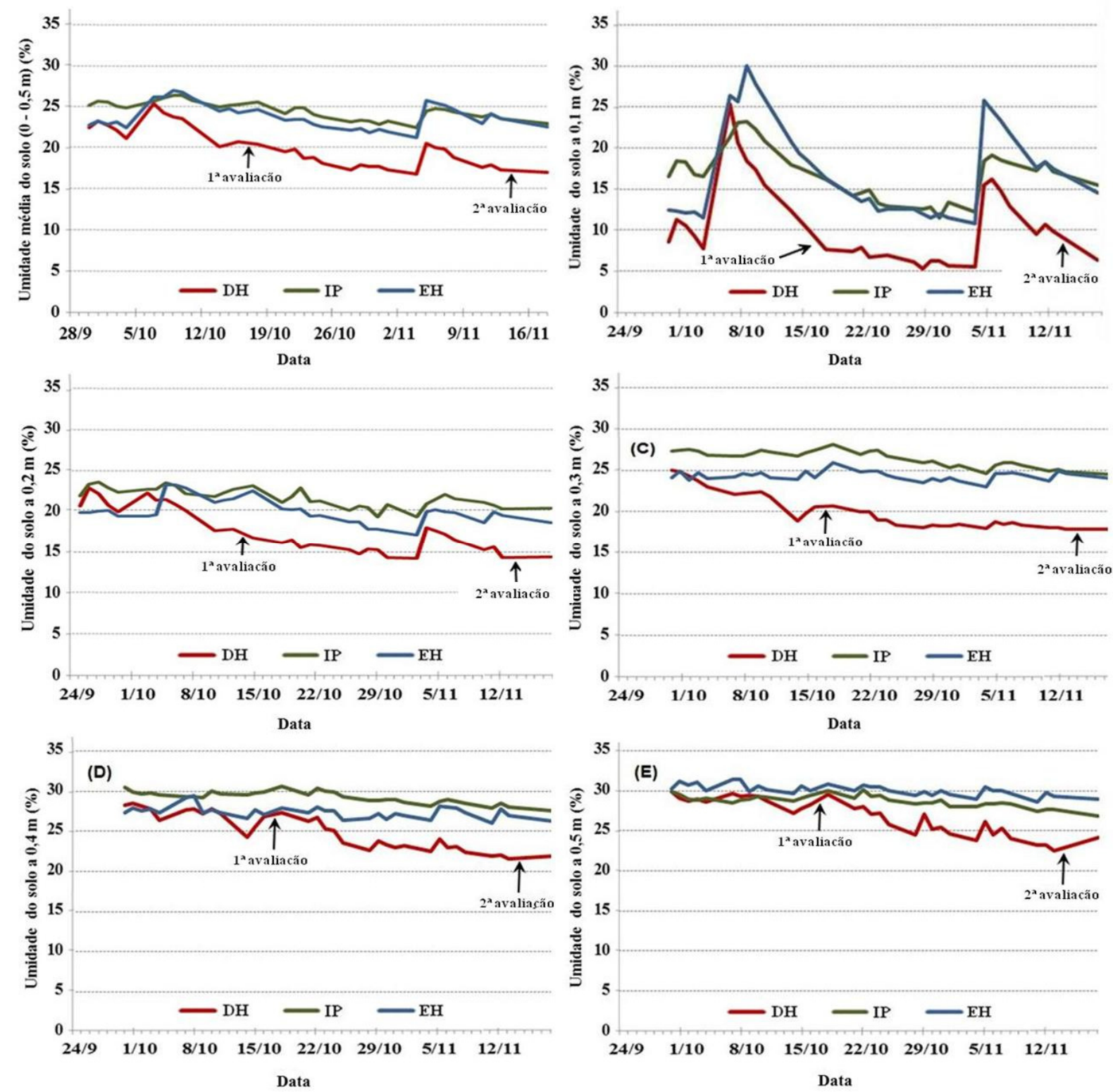

Figura 1. Umidade média do solo na camada de $0-0,5 \mathrm{~m}(\mathrm{~A})$ e em cada camada de solo, em cada regime hídrico. $\mathrm{B}=0,10 \mathrm{~m} ; \mathrm{C}=0,20 \mathrm{~m} ; \mathrm{D}=0,30 \mathrm{~m} ; \mathrm{E}=0,40 \mathrm{~m} ; \mathrm{F}=0,50 \mathrm{~m} ; \mathrm{CC}=30 \% ; \mathrm{PMP}=15 \% ; \mathrm{UC}=22,5 \%$.

As linhas de umidade do solo foram decaindo com a duração do período de imposição dos regimes hídricos, indicando um efeito cumulativo da aplicação diferenciada das lâminas de irrigação sobre o conteúdo de água no solo. De fato, por ocasião da $1^{\text {a }}$ avaliação (15 DAI), os conteúdos de água no solo com a imposição do regime de DH foi de $18 \%$, reduzindo-se para $15 \%$ na $2^{\mathrm{a}}$ avaliação (45 DAI) (Figura 1). Os picos de umidade do solo ocorridos um pouco antes da $2^{\mathrm{a}}$ avaliação foram devidos aos registros de precipitação, que embora tendo sido pequenos, foram suficientes para alterar o conteúdo de água no solo, notadamente, na camada de $0,1 \mathrm{~m}$ (Figura
1B). Porém, o rápido decréscimo nas curvas de umidade do solo, nas camadas de $0,1 \mathrm{~m}$ e $0,2 \mathrm{~m}$ (Figura 1BC), associados ao fato de não terem ocorridos na camada de $0,3 \mathrm{~m}$ a $0,5 \mathrm{~m}$ (Figura 1DF), indicam que essa alteração não afetou de forma nítida os regimes hídricos impostos.

Em termos de camada de solo, observa-se que nas camadas superficiais de 0,1 e $0,2 \mathrm{~m}$ (Figura $1 \mathrm{AB}$ ) ocorreram as maiores flutuações no conteúdo de água no solo, devido principalmente a localização da linha gotejadora, que foi enterrada a $0,25 \mathrm{~m}$ de profundidade no solo. $\mathrm{Na}$ camada superficial de $0,1 \mathrm{~m}$, no regime de $\mathrm{DH}$, foram registrados valores de umidade do solo de 
apenas $7 \%$, portanto, próximos ao ponto de murcha permanente do solo. Além da localização da linha gotejadora, acredita-se que a evaporação de água no solo tenha sido responsável pela redução da umidade nessa camada. Ressalta-se que, mesmo sendo enterrada a $0,25 \mathrm{~m}$ de profundidade no solo, a linha gotejadora promoveu a formação de bulbo molhado na superfície do solo, não reduzindo por completo o efeito da evaporação de água.

Para todos os parâmetros fisiológicos avaliados, a interação tripla regimes hídricos $(\mathrm{RH})$ $\mathrm{x}$ cultivares (CULT) x épocas de avaliação (EP) foi significativa, indicando que as cultivares de cana-de-açúcar avaliadas apresentaram respostas fisiológicas distintas, dependendo do regime hídrico e da época de avaliação (Tabela 2).

Tabela 2. Resumo da análise de variância para fotossíntese (A), condutância estomática $\left(\mathrm{g}_{\mathrm{s}}\right)$ e transpiração (E) das cultivares em função dos regimes hídricos e épocas de avaliação.

\begin{tabular}{lcccc}
\hline FV & GL & & Quadrados médios & \\
& & Fotossíntese $(\mathbf{A})$ & Condutância (gs) & Transpiração (E) \\
\hline BL & 3 & $5,235^{\mathrm{ns}}$ & $0,000577^{\mathrm{ns}}$ & $0,705^{\mathrm{ns}}$ \\
RH & 2 & $1960,476^{* *}$ & $0,105753^{* *}$ & $27,549^{\mathrm{ns}}$ \\
BL X RH ERROS (a) & 6 & 38,814 & 0,001000 & 8,559 \\
CULT. & 4 & $653,202^{* *}$ & $0,025774^{*}$ & $22,526^{* *}$ \\
RH X CULT. & 8 & $201,895^{* *}$ & $0,007165^{* *}$ & $6,292^{* *}$ \\
BL X CULT (RH) ERROS (b) & 36 & 32,594 & 0,001000 & 1,724 \\
EP & 1 & $1719,290^{* *}$ & $0,058735^{* *}$ & $84,842^{* *}$ \\
RH X EP & 2 & $1361,544^{* *}$ & $0,0223231^{\text {ns }}$ & $48,058^{* *}$ \\
CULT. X EP & 4 & $363,995^{* *}$ & $0,001496^{\mathrm{ns}}$ & $1,379^{\mathrm{ns}}$ \\
RH X CULT. X EP & 8 & $565,179^{* *}$ & $0,00318728^{* *}$ & $2,059^{*}$ \\
ERROS (c) & 45 & 20,580 & 0,001000 & 0,902 \\
\hline CV (a) & - & 21,170 & 19,040 & 44,130 \\
CV (b) & - & 19,390 & 24,007 & 19,800 \\
CV (c) & - & 15,410 & 17,640 & 14,330 \\
\hline
\end{tabular}

$1 * \mathrm{e}^{* *}$ - significativo a $5 \%$ e a $1 \%$ de probabilidade, respectivamente, ${ }^{\text {ns }}$ - não significativo.

Conforme o regime de $\mathrm{DH}$, estatisticamente, todas as cultivares do ensaio apresentaram desempenho fotossintético semelhante na primeira época (Figura 2A).

Quanto à segunda época, a cultivar SP 791011 mostrou desempenho fotossintético inferior as demais. Em valores absolutos, as melhores taxas fotossintéticas foram apresentadas pelas cultivares RB962962 e VAT90212, com $16,03 \mu \mathrm{mol} \cdot \mathrm{m}^{-2} \cdot \mathrm{s}^{-1}$ e $18,78 \mu \mathrm{mol} \cdot \mathrm{m}^{-2} . \mathrm{s}^{-1} 45$ DAI, respectivamente. Esse resultado comprova a característica de tolerância a seca inerente do cultivar RB962962.

$\mathrm{Na}$ segunda época houve variação significativa dos regimes hídricos impostos às cultivares (Figura 2B). Analisando as cultivares entre si, observou-se que, estatisticamente para o regime $\mathrm{DH}$, as mesmas obtiveram uma alta taxa de redução no desempenho fotossintético visto que não foram consideradas iguais em relação aos regimes IP e EH. A cultivar RB962962 mostrou igual desempenho fotossintético para com os regimes IP e EH, bem como a cultivar RB98710.

$\mathrm{O}$ regime $\mathrm{EH}$ foi considerado, estatisticamente, o melhor para a cultivar RB867515, indicando que neste regime mostrou seu melhor desempenho fotossintético.

Ao se analisar as épocas de avaliação ocorreram variações apenas na taxa de condutância das cultivares, quando as mesmas foram submetidas ao regime de deficiência hídrica (Figura 3). 

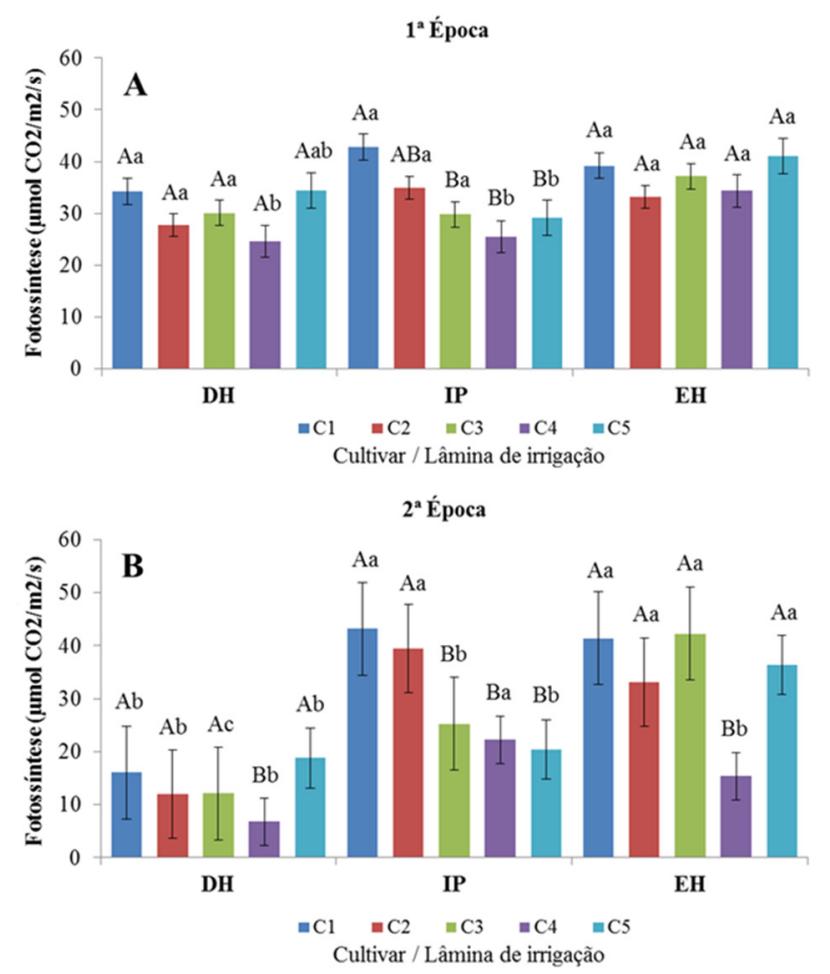

Figura 2. Médias de fotossíntese em duas épocas de avaliação, em resposta aos regimes hídricos diferenciados, comparando as mesmas cultivares entre si dentro de cada regime e entre cultivares dentro do mesmo regime hídrico. *Médias seguidas pela mesma letra maiúscula significa que não há diferença entre as cultivares, dentro do mesmo regime, e médias seguidas pela mesma letra minúscula significa que não há diferença entre as cultivares nos distintos regimes (nível de 5\% de probabilidade pelo teste Tukey).
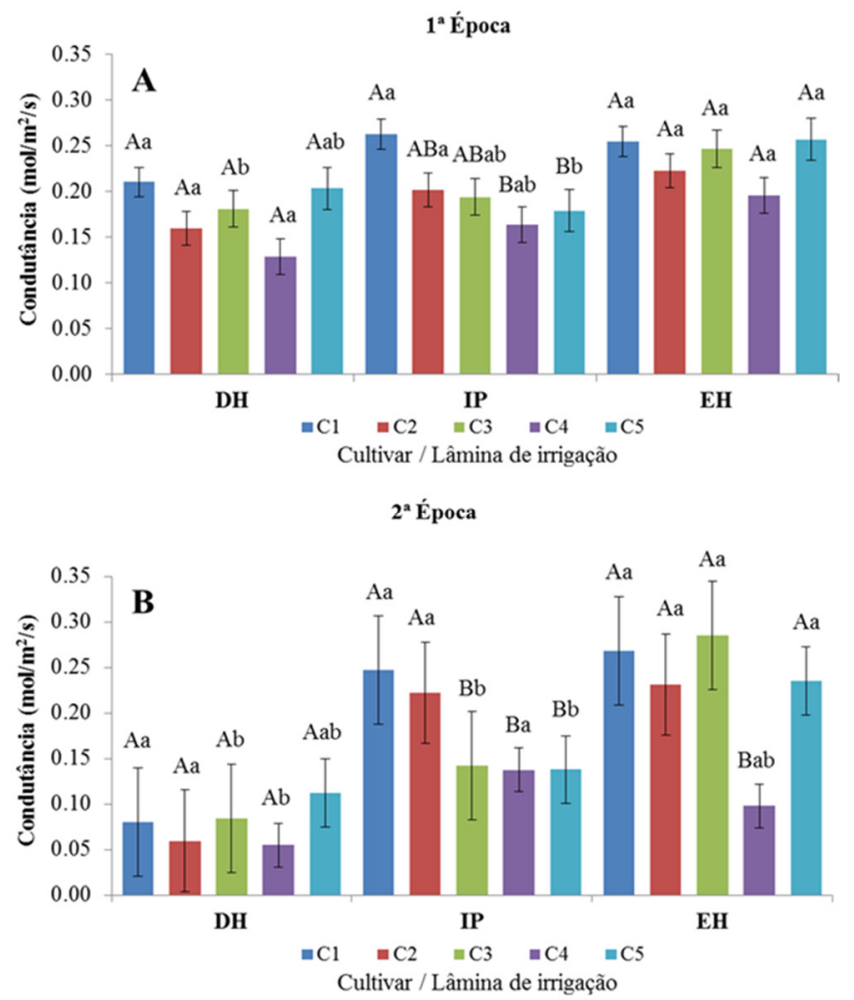

Figura 3. Médias de condutância em duas épocas de avaliação, em resposta aos regimes hídricos diferenciados, comparando as mesmas cultivares entre si dentro de cada regime e entre cultivares dentro do mesmo regime hídrico. *Médias seguidas pela mesma letra maiúscula significa que não há diferença entre as cultivares, dentro do mesmo regime, e médias seguidas pela mesma letra minúscula significa que não há diferença entre as cultivares nos distintos regimes (nível de 5\% de probabilidade pelo teste Tukey). 
Foi observado de maneira geral, redução de $45,0 \%$ para cultivar VAT90212 e $62,58 \%$ para RB98710 nos valores de condutância estomática em comparação entre épocas.

Considerando o regime de $\mathrm{DH}$, a cultivar VAT90212 apresentou redução na taxa de condutância (de $0,18 \mathrm{~mol} \cdot \mathrm{m}^{-2} \cdot \mathrm{s}^{-1}$ aos $15 \mathrm{DAI}$, para 0,14 mol. $\left.\mathrm{m}^{-2} \cdot \mathrm{s}^{-1}\right)$, aos 45 DAI, apesar de permanecer com os níveis adequados de conteúdo de água no solo próximos à capacidade de campo, tanto aos 15 como aos 45 DAI. Não se observou diferença significativa nas taxas de condutância entre as duas épocas de avaliação (Figura 1).

Por outro lado, a cultivar SP791011 apresentou redução na taxa de condutância de $0,20 \mathrm{~mol} \cdot \mathrm{m}^{-2} \cdot \mathrm{s}^{-1}$, aos $15 \mathrm{DAI}$, para $0,10 \mathrm{~mol} \cdot \mathrm{m}^{-2} \cdot \mathrm{s}^{-1}$ aos $45 \mathrm{DAI}$, quando submetida ao regime de EH. De fato, aos 45 DAI, sob regime de IP, essa cultivar apresentou taxa de condutância 0,14 de mol. $\mathrm{m}^{-2} \cdot \mathrm{s}^{-1}$, portanto, superior ao valor de 0,05 mol. $\mathrm{m}^{-2} \cdot \mathrm{s}^{-1}$, registrado em DH, e de $0,10 \mathrm{~mol} . \mathrm{m}^{-}$ ${ }^{2} . \mathrm{s}^{-1}$ sob regime de $\mathrm{EH}$.
Perante regime de IP e EH, a cultivar RB962962 apresentou a maior taxa de condutância, em ambas as épocas. Sob EH a cultivar RB962962 apresentou taxas iguais a 0,25 mol. $\mathrm{m}^{-2} \cdot \mathrm{s}^{-1}$ e $0,27 \mathrm{~mol} \cdot \mathrm{m}^{-2} \cdot \mathrm{s}^{-1}$, aos 15 e 45 DAI, respectivamente.

Sob regime de $\mathrm{DH}$, estatisticamente, não ocorreu diferenças significativa na condutância entre todas as cultivares. Porém, em valores absolutos, as melhores taxas foram apresentadas pelas cultivares RB962962, RB867515 e VAT90212, com $0,08 \mathrm{~mol} \cdot \mathrm{m}^{-2} \cdot \mathrm{s}^{-1}, 0,08 \mathrm{~mol} \cdot \mathrm{m}^{-2} \cdot \mathrm{s}^{-1}$ e $0,11 \mathrm{~mol} \cdot \mathrm{m}^{-2} \cdot \mathrm{s}^{-1}$, respectivamente, mesmo após decorridos 45 dias após o início da imposição dos regimes hídricos diferenciados.

Ao se fazer a análise em relação à época de avaliação, foi observada variação apenas na transpiração das cultivares, quando essas estavam submetidas ao regime de deficiência hídrica (Figura 4).

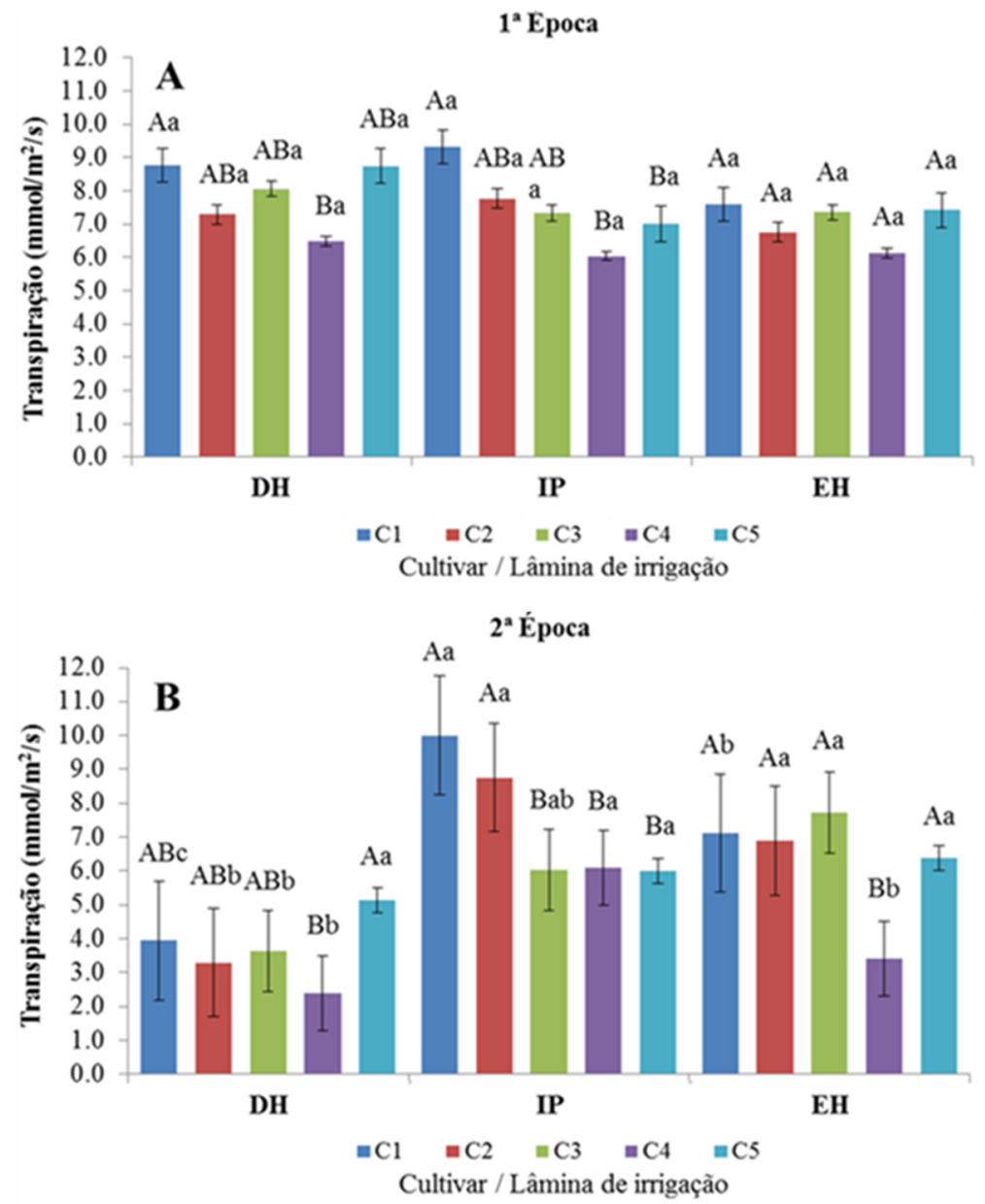

Figura 4. Médias de transpiração em duas épocas de avaliação, em resposta aos regimes hídricos diferenciados, comparando as mesmas cultivares entre si dentro de cada regime e entre cultivares dentro do mesmo regime hídrico. *Médias seguidas pela mesma letra maiúscula significa que não há diferença entre as cultivares, dentro do mesmo regime, e médias seguidas pela mesma letra minúscula significa que não há diferença entre as cultivares nos distintos regimes (nível de 5\% de probabilidade pelo teste Tukey). 
Foi observada, no geral, uma redução de $41,14 \%$ (VAT90212) a 54,83\% (RB867515) nos valores de transpiração entre as cultivares. Redução semelhante foi observado em genótipos de milho por Cruz (2006), com exceção para a cultivar SP791011, foi a que apresentou o maior percentual de queda, passando de 6,13 mmol.m ${ }^{2} \cdot \mathrm{s}^{-1}$, aos 15 DAI, para $3,41 \mathrm{mmol} \cdot \mathrm{m}^{-2} \cdot \mathrm{s}^{-1}$, aos 45 DAI. A cultivar SP791011 apresentou redução significativa nos valores médios de taxa de transpiração nas duas épocas de avaliação, em DH de 6,49 mmol. $\mathrm{m}^{-2}$, aos $15 \mathrm{DAI}$, para 2,40 mmol. $\mathrm{m}^{-}$ ${ }^{2} . \mathrm{s}^{-1}$, aos $45 \mathrm{DAI}$ ) e em EH de 6,13 mmol.m ${ }^{-2}$, aos 15 DAI, para 3,41 mmol. $\mathrm{m}^{-2} \cdot \mathrm{s}^{-1}$, aos $\left.45 \mathrm{DAI}\right)$. .

\section{Discussão}

Os regimes hídricos diferenciados foram aplicados no período de 30 de setembro a 22 de novembro de 2013, devido ao fato de nesta época não haver registros históricos de precipitação, que pudesse prejudicar a imposição dos regimes hídricos desejados. Porém, mesmo com essa precaução houve o registro de $6,8 \mathrm{~mm}$ de precipitação, no período de aplicação dos regimes hídricos diferenciados.

A evapotranspiração de referência (ETo) acumulada foi de $437 \mathrm{~mm}$ durante o período experimental, valor esse utilizado para a estimativa dos regimes hídricos diferenciados, permitindo uma adequada diferenciação entre os mesmos. Em termos diários, a ETo variou entre 6,0 e 7,0 mm, indicando ter havido elevada extração de água do solo pela cana-de-açúcar, com esperados reflexos nas taxas fisiológicas das cultivares avaliadas.

Considerando os resultados encontrados, verificou-se uma elevada extração de água do solo pela cana-de-açúcar, com esperados reflexos nas taxas fisiológicas das cultivares avaliada.

As maiores taxas fotossintéticas em termos absolutos apresentada pela a cultivar RB962962 e VAT90212. Esse resultado comprova a característica de tolerância a seca inerente da cultivar RB962962. Contudo, o mesmo não se aplica a cultivar VAT 90212, que apesar de ser indicada para cultivo em solos úmidos de várzea (RIDESA, 2010), mostrou-se também fisiologicamente indicada para cultivo em solos mais secos.

Com relação à época de avaliação, a variações na taxa de condutância das cultivares, quando submetidas ao regime de deficiência hídrica, indicando que a forte redução no conteúdo de água observado entre as duas épocas de avaliação, influenciou a condutância estomática (Schulze et al., 1987). Resultados semelhantes foram relatados por Smith \& Singels
(2006), que notaram reduções na condutância estomática em variedades de cana-de-açúcar, afirmando, que tal variável apresenta maior sensibilidade que o potencial hídrico à medida que o solo se torna mais seco.

A redução na taxa de condutância observada na cultivar VAT90212, para o regime de IP, pode ter ocorrido devido ao valor discrepante em uma das repetições, que afetou a média da variável, visto que no regime hídrico de $\mathrm{EH}$, onde se manteve valores e umidade do solo muito próximos aos da IP, não se observou diferença significativa nas taxas de condutância entre as duas épocas de avaliação. Por outro lado, a redução na taxa de condutância apresentada pela a cultivar SP791011 indica que a mesma é sensível à manutenção de elevado conteúdo de água no solo, devendo ser indicada para ambientes mais secos. Aos 45 DAI, sob regime de IP, essa cultivar apresentou taxa de condutância, superior registrado em DH, sob regime de EH. Confirmando, a característica de ser mais responsiva a água que tolerante à seca, com valores próximos aos obtidos por Gonçalves et al. (2010), ao avaliar as trocas gasosas e fluorescência da clorofila em variedades de canade-açúcar submetidas à deficiência hídrica. A redução na disponibilidade de água no solo promove a queda no potencial da água nas folhas das plantas, levando à redução da condutância estomática (Shalhevet, 1983).

A maior taxa de condutância apresentado para a cultivar RB962962 em regime de IP e EH, em ambas as épocas, indicando que a mesma é responsiva ao fator água. Com relação à época de avaliação, a variação observada na transpiração das cultivares, mostrando que a forte redução da disponibilidade de água entre as duas épocas de avaliação, induzindo o fechamento dos estômatos, evitando a perda de água das folhas, com consequente redução na taxa da transpiração (Mansfield \& Davies, 1985).

Foi observado no geral uma redução de $41,14 \%$ (VAT90212) a 54,83\% (RB867515) nos valores de transpiração entre as cultivares. Redução semelhante foi observado em genótipos de milho por Cruz (2006), com exceção para a cultivar 8 (SP 791011), foi a que apresentou o maior percentual de queda $(63,02 \%)$.

A redução nos valores médios de taxa de transpiração nas duas épocas de avaliação apresentada pela cultivar SP791011 em EH, indicando possível sensibilidade da mesma a elevado conteúdo de água no solo, devendo ser indicada para ambientes mais secos.

Sob regime de IP e EH, as maiores taxas de transpiração apresentada pela a cultivar 
RB962962, nas duas épocas de avaliação, indica que as mesmas, respondem ao fator água.

As cultivares RB962962, RB98710, RB867515 e VAT90212 sob DH apresentaram transpiração semelhante nas duas épocas de avaliação. Resultado que comprova a característica de tolerância à seca na cultivar RB962962 e para cultivar VAT90212, mesmo esta última sendo indicada para cultivo em solos úmidos de várzea (RIDESA, 2010), mostrou-se também fisiologicamente indicada para cultivo em solos mais secos.

\section{Conclusão}

A variedade RB 962962 apresenta desempenho fisiológico superior às demais, quando submetida ao regime de deficiência hídrica, ao passo que em condições de irrigação plena e excedente hídrico as variedades RB 962962 e RB 98710 promovem as maiores médias de fotossíntese, condutância estomática e transpiração.

A variedade SP 791011 apresenta maior sensibilidade estomática, com redução da fotossíntese, condutância estomática e transpiração quando cultivada, tanto sob regime de deficiência quanto de excedente hídrico no solo.

\section{Agradecimentos}

Os autores agradecem à Embrapa MeioNorte pelo financiamento do projeto e disponibilização do espaço físico e mão de obra de pessoal para a realização do experimento; ao Conselho Nacional de Desenvolvimento Científico (CNPq) pela concessão de bolsa de estudos.

\section{Referências}

ALLEN, R. G.; PEREIRA, L. S.; RAES, D.; SMITH, M. 1998. Crop evapotranspiration: guidelines for computing crop water requirements. Roma: FAO. (FAO Irrigation and Drainage Paper, 56). $328 \mathrm{p}$.

BASTOS, E. A.; ANDRADE JUNIOR, A. S. 2014. Boletim agrometeorológico de 2013 para o município de Teresina, Piauí. Teresina: Embrapa Meio-Norte. (Documento/Embrapa Meio-Norte). $38 \mathrm{p}$.

CHAVES, M. M. 1987.Gas exchange studies in two Portuguese grapevine cultivars. Physiologia Plantarum, v. 70, n. 4, p. 639-647.
INMAN-BAMBER, N. G. 2004. Sugarcane water stress criteria for irrigation and drying off. Field Crops Research, v. 89, n. 1, p. 107-122.

INMAN-BAMBER, N. G.; SMITH, D. M. 2005. Water relations in sugarcane and response to water deficits. Field Crops Research, v. 92, n. 2, p. 185-202.

LANDELL, M. G. A.; CAMPANA, M. P.; FIGUEIREDO, P.; VASCONCELOS, A. C. M.; XAVIER, M. A.; BIDOIA, M. A. P.; PRADO, H.; SILVA, M. A.; MIRANDA, L. L. D.; AZANIA, C. A. M. 2005. Variedades de cana-de-açúcar para o Centro-Sul do Brasil. Campinas: Instituto Agronômico. (Boletim Técnico, 197). 33p.

MACHADO, R. S.; RIBEIRO, R. V.; MARCHIORI, P. E. R.; MACHADO, D. F. S. P.; MACHADO, E. C.; LANDELL, M. G. DE A. 2010. Respostas biométricas e fisiológicas ao déficit hídrico em cana-de-açúcar em diferentes fases fenológicas. Pesquisa Agropecuária Brasileira, v. 44, n. 12, p. 1575-1582.

MAPA. 2013. Ministério da Agricultura, Pecuária e Abastecimento. Cana-de-açúcar. Disponível em: http://www.agricultura.gov.br/vegetal/culturas/can a-de-acucar. Acesso em: 05 de março de 2013.

MELO, F. B.; ANDRADE JÚNIOR, A. S.; PESSOA, B. L. O. 2014. Levantamento, zoneamento e mapeamento pedológico detalhado da área experimental da Embrapa Meio-Norte em Teresina, PI. Teresina: Embrapa Meio-Norte. (Documentos/Embrapa Meio-Norte). 47p.

MUNNS, R. 2002. Comparative physiology of salt and water stress. Plant, Cell and Environment, v. 25 , p. $239-250$.

RIDESA-Rede Interuniversitária para o Desenvolvimento do Setor Sucroalcooleiro. 2010. Catálogo nacional de variedades "RB" de canade-açúcar / Rede Interuniversitária para o Desenvolvimento do Setor Sucroalcooleiro. Curitiba.

SAS Institute. 2014. Statistical Analysis System, Procedure guide for personal computer, Cary.

SCHULZE, E. D.; TURNER, N. C.; GOLLAN, T.; SHACKEL, K. A. 1987. Stomatal Responses to Air Humidity and to Soil Drought. In: ZEIGER, E.; FARQUHAR, G. D.; COWAN, I. R. (Org). Stomatal function. Stanford University Press. 
Journal of Environmental Analysis and Progress V. 02 N. 04 (2017) 509-518

SHALHEVET, J. 1983. Plants under salt and water stress. In: FOWDEN, L.; MANSFIELD, T.; STODDART, J. Plant adaptation to environmental stress. London: Chapman \& Hall. Cap. 7, pp. 13354.
SMITH, M. A.; SINGELS, A. 2006. The response of sugarcane canopy development to water stress. Field Crops Research, Cambridge, v. 98, p. 91-97. 